\title{
Detection of Viruses and Virus-Neutralizing Antibodies Using Synthetic Erythrocytes: Toward a Tuneable Tool for Virus Surveillance
}

\section{Supplementary Information}

Ana Sánchez-Cano ${ }^{1,2}$, Cristina Andrés ${ }^{3}$, José R. Herance ${ }^{4}$, Tomás Pumarola ${ }^{2,3}$, Andrés Antón $^{2,3}$, Eva Baldrich*1,5

${ }^{1}$ Diagnostic Nanotools Group, CIBBIM -Nanomedicine, Vall d'Hebron Institut de Recerca (VHIR), Vall d’Hebron Barcelona Hospital Campus, Barcelona 08035, Spain.

${ }^{2}$ Universitat Autònoma de Barcelona (UAB), Bellaterra, Barcelona 08193, Spain.

${ }^{3}$ Respiratory Viruses Unit, Microbiology Department, Vall d'Hebron Hospital Universitari, Vall d'Hebron Barcelona Hospital Campus, Barcelona 08035, Spain.

${ }^{4}$ Medical Molecular Imaging Group, Vall d'Hebron Institut de Recerca (VHIR), Vall d'Hebron Barcelona Hospital Campus, Barcelona 08035, Spain.

${ }^{5}$ CIBER de Bioingeniería, Biomateriales y Nanomedicina (CIBER-BBN), Spain.

*Corresponding Author: eva.baldrich@ vhir.org. Hospital Vall d'Hebron. Passeig de la Vall d'Hebron, 119-129 - 08035 Barcelona. 


\section{Table of contents:}

\section{Reagents}

Table S1. Properties of tested microparticles.

Table S2. Characteristics of the sialylated proteins evaluated.

\section{Results}

Figure S1. Scheme of the sandwich ELISA optimized for the characterization of bioreceptor candidates.

Figure S2. Sedimentation of agglutinated and non-agglutinated particles of different materials.

Figure S3. Sedimentation pattern of 5 and $10 \mu \mathrm{m}$ Sicastar-blue beads in 3 types of 96-well microtiter plates.

Figure S4. Optimization of a sandwich ELISA for bioreceptor candidate evaluation.

Figure S5. Influence of temperature and incubation time in virus-bioreceptor recognition.

Figure S6. Changes in sedimentation of sialylated beads in the presence of lectins.

Figure S7. Impact of $\mathrm{pH}$ in the sedimentation of sialylated microparticles.

Figure S8. Effect of size of the sialylated beads in sedimentation capacity.

Figure S9. Behavior of EDC- and glutaraldehyde-conjugated GYPA-particles in absence or presence of WGA lectin.

Figure S10. Optimization of bead conjugation and assay.

Figure S11. Titration of the WHO reference antigens using alternatively synthrocytes ${ }^{\circledR}$ or human RBCs.

\section{Description of downloadable Supplementary material}

Video 1. Sedimentation of Sicastar blue particles in the presence of an agglutinating lectin.

Video 2. Sedimentation of synthrocytes in the presence of influenza virus. 


\section{Reagents}

Table S1. Properties of tested microparticles. ns, stands for not stated by the provider.

\begin{tabular}{|c|c|c|c|c|c|c|}
\hline Provider & Particle & $\begin{array}{c}\text { Material } \\
\text { (color) }\end{array}$ & $\begin{array}{l}\text { Density } \\
\text { (g/ccm) }\end{array}$ & Surface & $\begin{array}{c}\text { Diameter } \\
(\mu \mathrm{m})\end{array}$ & Type (ref) \\
\hline \multirow{9}{*}{$\begin{array}{l}\text { Micromod } \\
\text { (Germany) }\end{array}$} & \multirow{4}{*}{$\begin{array}{l}\text { Sicastar - } \\
\quad \text { blue }\end{array}$} & \multirow{4}{*}{ Silica (blue) } & \multirow{4}{*}{1.8} & \multirow{3}{*}{$\mathrm{NH}_{2}$} & 10 & 1 (73-01-104) \\
\hline & & & & & 5 & $2(73-01-503)$ \\
\hline & & & & & 3 & $3(73-01-303)$ \\
\hline & & & & $\mathrm{COOH}$ & 5 & $\begin{array}{l}4 \text { (Custom- } \\
\text { made) }\end{array}$ \\
\hline & \multirow{3}{*}{$\begin{array}{l}\text { PLA-blue } \\
\text { Sicastar }\end{array}$} & \multirow{3}{*}{$\begin{array}{l}\text { Poly(D,L- } \\
\text { lactic acid) } \\
\text { (blue) }\end{array}$} & \multirow{3}{*}{1.0} & \multirow{3}{*}{$\mathrm{NH}_{2}$} & 30 & $5(54-01-304)$ \\
\hline & & & & & 2 & $6(54-01-203)$ \\
\hline & & & & & 0.5 & $7(54-01-502)$ \\
\hline & Sicastar-M & $\begin{array}{c}\text { Magnetic } \\
\text { silica (brown) }\end{array}$ & 2.5 & $\mathrm{NH}_{2}$ & 1.5 & $8(39-01-153)$ \\
\hline & $\begin{array}{c}\text { Sicastar-M- } \\
\text { CT }\end{array}$ & $\begin{array}{l}\text { Cluster-typed } \\
\text { magnetic silica } \\
\text { (brown) }\end{array}$ & 2.5 & $\mathrm{NH}_{2}$ & 6 & $9(59-01-603)$ \\
\hline \multirow{2}{*}{$\begin{array}{c}\text { Bangs } \\
\text { Laboratories } \\
\text { (USA) }\end{array}$} & ProMag 3 & $\begin{array}{c}\text { Polymer and } \\
\text { iron oxide } \\
\text { (brown) }\end{array}$ & 1.6 & $\mathrm{COOH}$ & 2.75 & $10(\mathrm{PMC} 3 \mathrm{~N})$ \\
\hline & $\begin{array}{c}\text { ProMag HP } \\
3\end{array}$ & $\begin{array}{c}\text { Polymer and } \\
\text { iron oxide } \\
\text { (brown) }\end{array}$ & 1.4 & $\mathrm{COOH}$ & 3.13 & 11 (РМC3НР) \\
\hline $\begin{array}{l}\text { Invitrogen } \\
\text { (USA) }\end{array}$ & $\begin{array}{l}\text { Dynabeads } \\
\text { M-270 } \\
\text { Amine }\end{array}$ & $\begin{array}{c}\text { Polystyrene } \\
\text { with magnetic } \\
\text { material }\end{array}$ & ns & $\mathrm{NH}_{2}$ & 2.70 & 12 (14307D) \\
\hline
\end{tabular}


Table S2. Characteristics of the sialylated proteins evaluated. MW, molecular weight; ${ }^{[1]}$, Sigma-Merk; ${ }^{[2]}$, Thermo Fisher; ns, not stated by the provider. *Reports indicate that GYPA has a carbohydrate content ranging $40-80 \%{ }^{1}$ and accounts for $75 \%$ of the total sialic acid exhibited on the RBCs membrane., ${ }^{2,3}$

\begin{tabular}{|c|c|c|c|c|c|}
\hline Protein & Abbreviation & Origin & $\begin{array}{c}\text { Sialic Acid } \\
\text { content }\end{array}$ & $\begin{array}{c}\text { MW } \\
(\mathbf{k D a})\end{array}$ & $\begin{array}{c}\text { Isoelectric } \\
\text { point }\end{array}$ \\
\hline $\begin{array}{l}\text { Glycophorin } \\
{ }^{[1]}(\text { ref G5017) }\end{array}$ & GYPA & $\begin{array}{l}\text { Human } \\
\text { erythrocyte } \\
\text { membrane }\end{array}$ & $\mathrm{ns}^{*}$ & $50-80$ & $5.9-6.3$ \\
\hline $\begin{array}{l}\text { Bovine Mucin } \\
{ }^{[1]}(\text { ref M3895) }\end{array}$ & $\mathrm{BM}$ & $\begin{array}{l}\text { Submaxillary } \\
\text { glands }\end{array}$ & $9-24 \%$ & $\sim 1000$ & 3 \\
\hline $\begin{array}{l}\text { Porcine Mucin } \\
{ }^{[1]}(\text { ref M2378) }\end{array}$ & $\mathrm{PM}$ & $\begin{array}{l}\text { Stomach } \\
\text { mucus }\end{array}$ & $<1.2 \%$ & $\sim 1000$ & 3.5 \\
\hline $\begin{array}{c}\text { Avidin } \\
{ }^{[2]}(\text { ref 21121) }\end{array}$ & $\mathrm{Av}$ & Egg & ns & $67-68$ & 10 \\
\hline $\begin{array}{l}\text { Neutravidin } \\
{ }^{[2]}(\text { ref 31000) }\end{array}$ & NeuAv & Egg & deglycosylated & 60 & 6.3 \\
\hline
\end{tabular}




\section{Results}

Figure S1. Scheme of the sandwich ELISA optimized for the characterization of bioreceptor candidates.

Unless otherwise stated, incubations were performed in $100 \mu \mathrm{L}$ volumes, for $1 \mathrm{~h}$ and at $34{ }^{\circ} \mathrm{C}$, and were always followed by three consecutive washes with $200 \mu \mathrm{L}$ per well of washing buffer (PBS, 0.05\% Tween20).

Titrates were carried for each glycoprotein tested as a bioreceptor candidate. For this, a 2-fold dilution series of the glycoprotein (prepared in PBS) was immobilized in a 96-well high-binding plate by incubating overnight at $4{ }^{\circ} \mathrm{C}(50 \mu \mathrm{L} /$ well $)$. The wells were then blocked for $1 \mathrm{~h}$ at room temperature with $200 \mu \mathrm{L}$ of BSA $1 \%$. Three consecutive incubations followed, the first with decreasing concentrations of influenza virus or PBS as the negative control (90 min); the second with primary antibody (Ab; ref 3AH1, Hytest; diluted 1:10000 in PBS-BSA 1\%; 60 min); and the third with an HRP-labelled secondary Ab (Ab-HRP; ref A9044, Sigma Aldrich; diluted 1:30000 in PBS-BSA 1\%; $60 \mathrm{~min}$ ). Finally, the plate was washed 4 times and was incubated with TMB substrate solution for $20 \mathrm{~min}\left(100 \mu \mathrm{L} /\right.$ well). Stop solution was added $\left(50 \mu \mathrm{L} /\right.$ well of $\left.1 \mathrm{M} \mathrm{H}_{2} \mathrm{SO}_{4}\right)$ and the plate was read at $450 \mathrm{~nm}$.

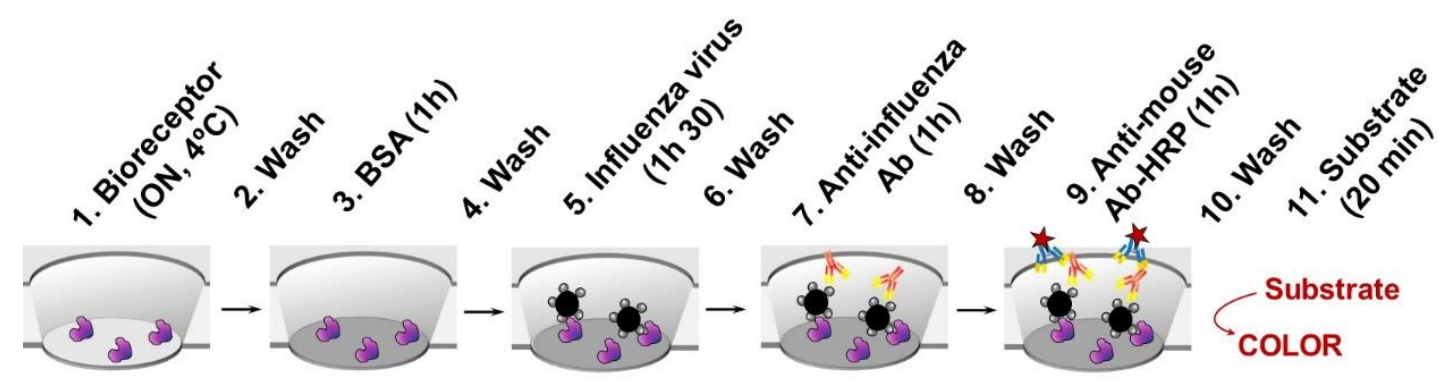

Bioreceptor Influenza virus Anti-influenza Ab Ab-HRP 
Figure S2. Sedimentation of agglutinated and non-agglutinated particles of different materials.

Examples of the sedimentation patterns of six types of commercial beads displaying amino groups on surface (Table S1). Beads were serially diluted 1:2 with PBS, were chemically crosslinked using an agglutinating agent (BS3, $2.5 \mathrm{mM}$ ) and were allowed to settle down in U-shaped wells.

None of the magnetic particles tested changed their sedimentation pattern upon agglutination.

On the other hand, polymeric beads, such as PLA-blue particles $2 \mu \mathrm{m}$ and $0.5 \mu \mathrm{m}$ in diameter, took between $>60$ min and $>24 \mathrm{~h}$ to settle down, which was longer than the sedimentation time exhibited by animal erythrocytes (30-60 min). They were also too light in color to be studied by the naked eye. Therefore, these particles were discarded.

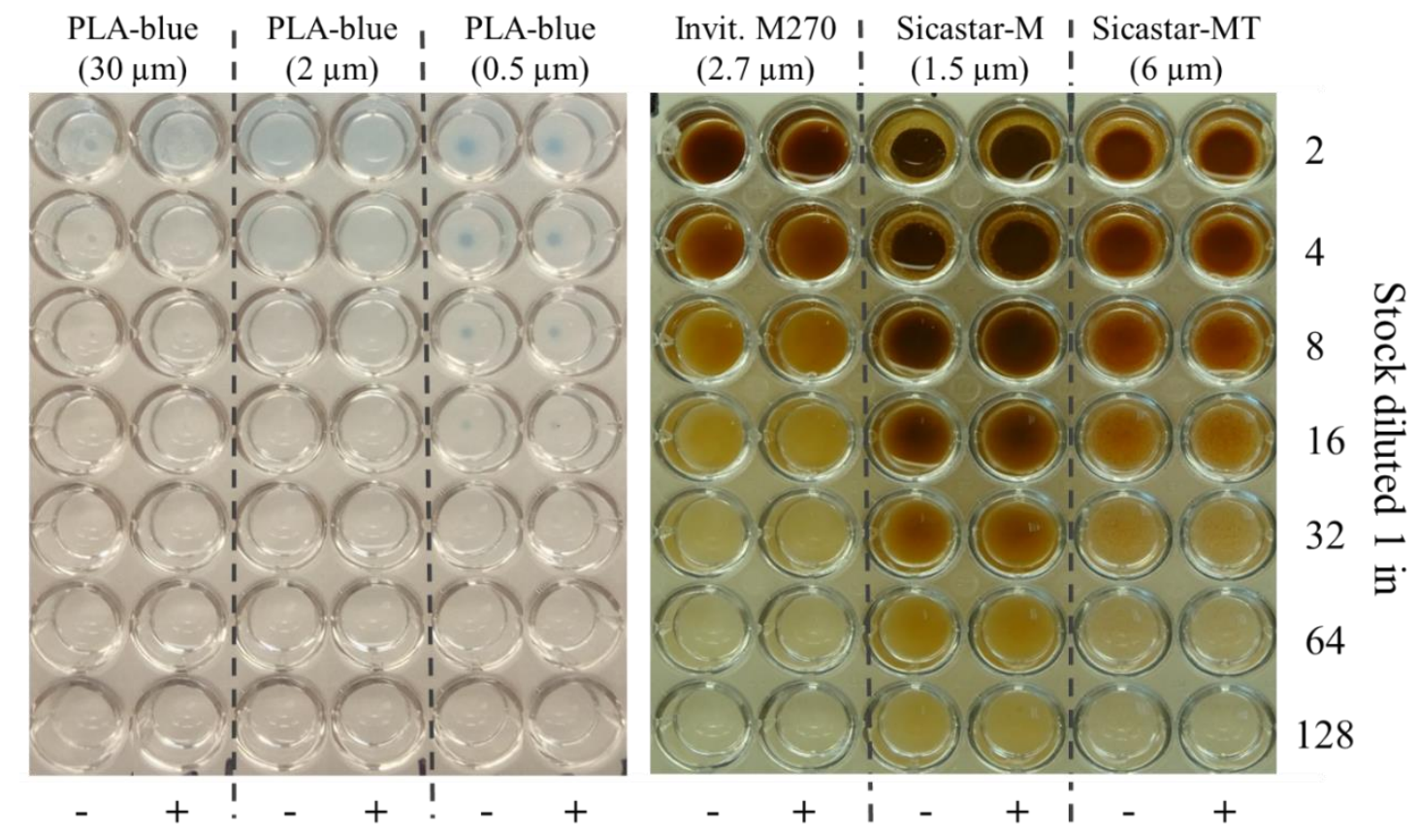

BS3 
Figure S3. Sedimentation pattern of 5 and $10 \mu \mathrm{m}$ Sicastar-blue beads in 3 types of 96-well microtiter plates.

Beads were diluted in PBS, containing or not a chemical crosslinker that promoted bead agglutination (BS3, 2.5 and $0 \mathrm{mM}$, respectively), and were allowed to settle down for $10 \mathrm{~min}$ before taking a picture in either V- (a), U- (b) or flat-bottomed (c) wells. Two bead dilutions are shown for each assay condition, including two replicates of each.

Both types of beads settled down forming a tight button at V-shaped wells, a behavior that reminded that of nucleated avian erythrocytes. In contrast, the sediments in U-shaped wells were broader and tended to form a ring. Mammalian erythrocytes, which are anucleated, are known to form ring-like sediments in U-shaped wells.

The differences in sedimentation of $5 \mu \mathrm{m}$ particles were only evident at U-shaped wells. In contrast, the differences in sedimentation displayed by $10 \mu \mathrm{m}$ microparticles, agglutinated or not, where observable at both $\mathrm{U}$ - and V-shaped wells, although they were slightly clearer in Vbottomed microtiter plates. No distinction could be made between free and agglutinated beads in flat-bottomed plates in none of the cases.

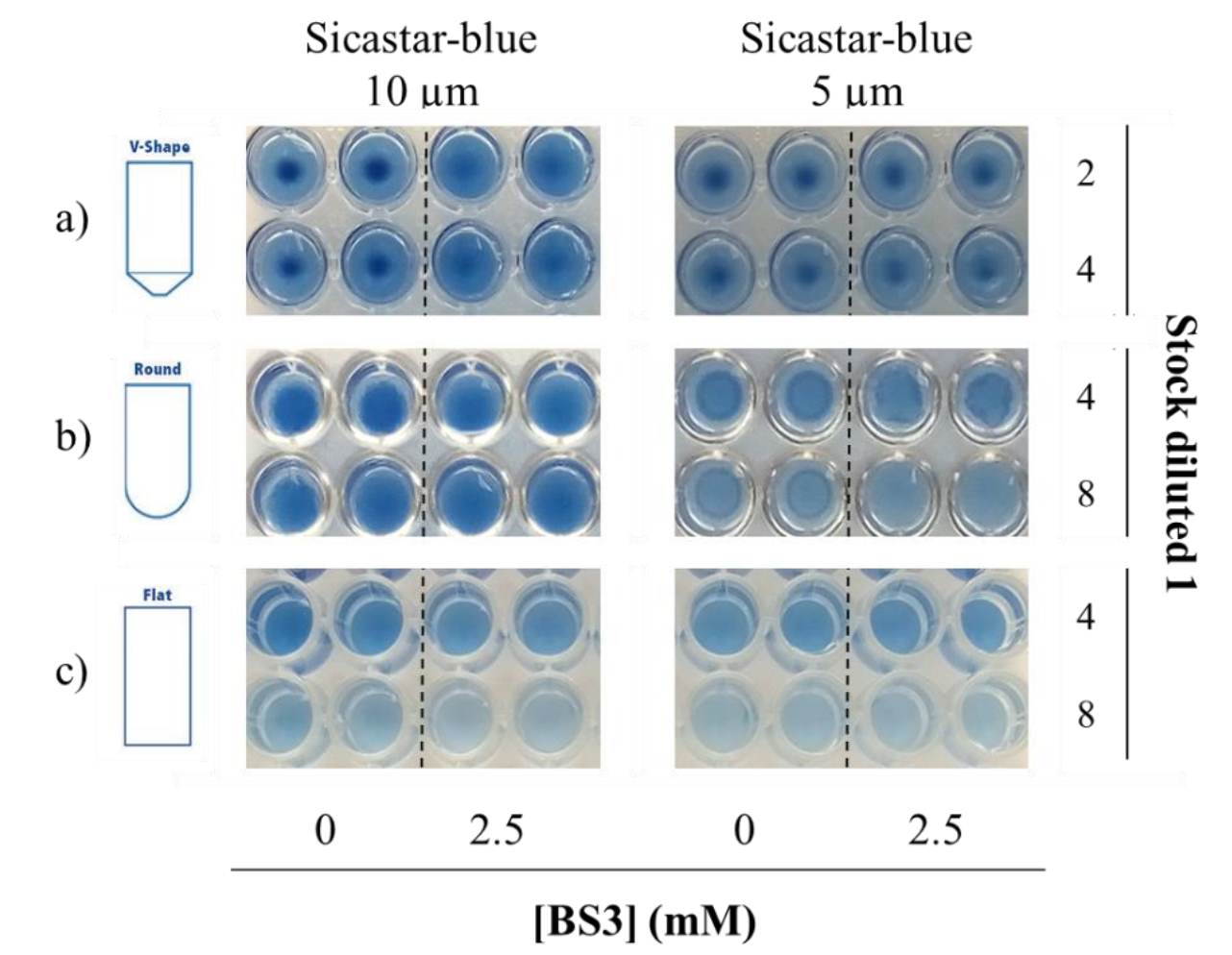




\section{Figure S4. Optimization of a sandwich ELISA for bioreceptor candidate evaluation.}

Binding of influenza $\mathrm{A}(\mathrm{H} 1 \mathrm{~N} 1) \mathrm{A} / \mathrm{NewCaledonia/20/99}$ by 5 different bioreceptor candidates. Each candidate was immobilized on surface at concentration ranging $0-40 \mu \mathrm{g} / \mathrm{mL}$, followed by incubation with increasing concentrations of influenza $\mathrm{A}(\mathrm{H} 1 \mathrm{~N} 1)$ and indirect immunodetection.
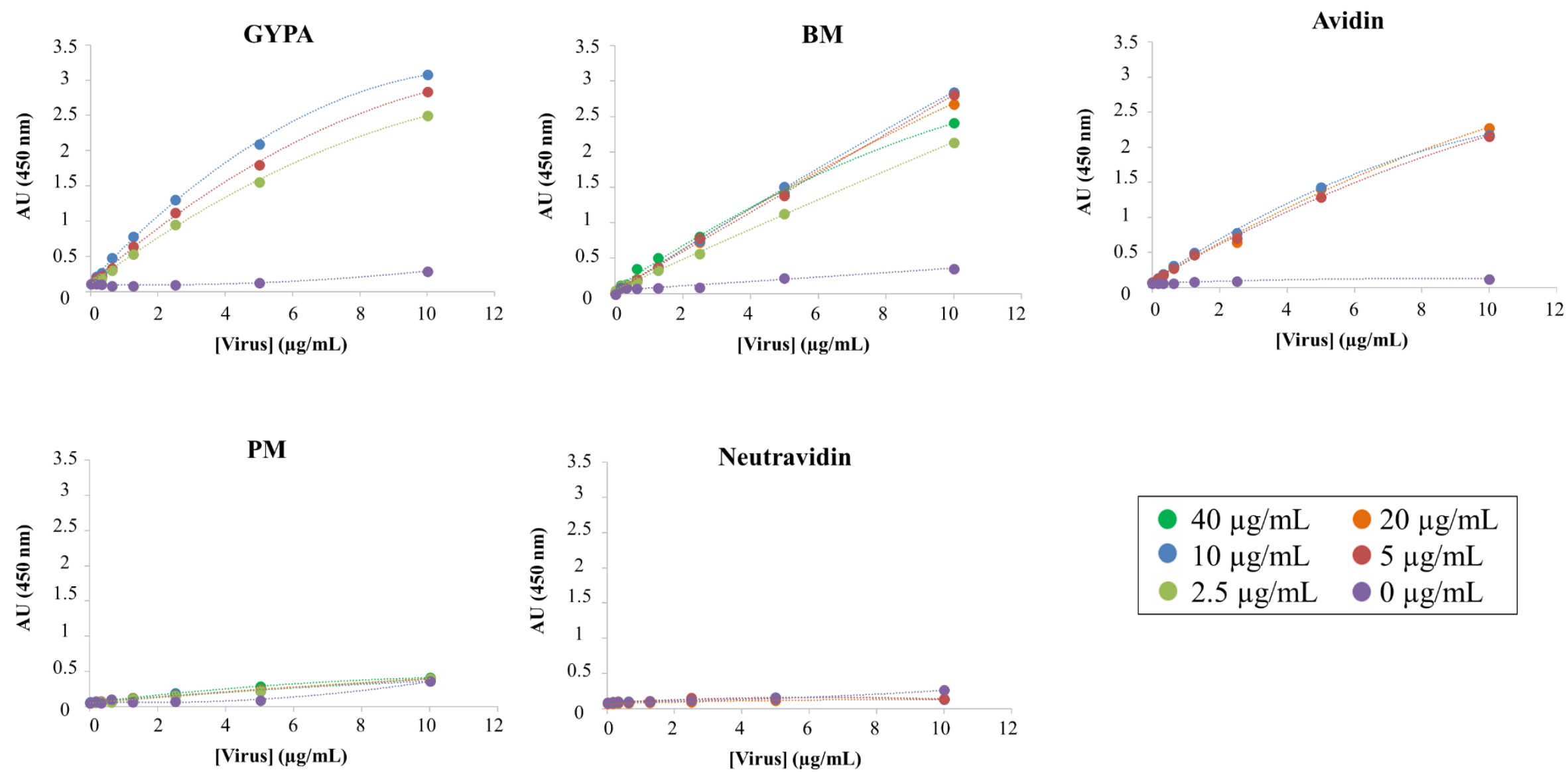

\begin{tabular}{|ll}
$40 \mu \mathrm{g} / \mathrm{mL}$ & $20 \mu \mathrm{g} / \mathrm{mL}$ \\
$10 \mu \mathrm{g} / \mathrm{mL}$ & $5 \mu \mathrm{g} / \mathrm{mL}$ \\
$2.5 \mu \mathrm{g} / \mathrm{mL}$ & $0 \mu \mathrm{g} / \mathrm{mL}$
\end{tabular}


Figure S5. Influence of temperature and incubation time in virus-bioreceptor recognition.

a) Signal-to-noise $(\mathrm{S} / \mathrm{N})$ ratios and equations corresponding to the ELISA shown in Fig. 2 of the main manuscript, performed for influenza-receptor affinity determination. b) ELISA in which the plate, modified with $20 \mu \mathrm{g} / \mathrm{ml}$ of $\mathrm{BM}$, was alternatively incubated at 24 or $34^{\circ} \mathrm{C}$ with a serial dilution of influenza H1N1 A/NewCaledonia/20/99. Although incubating at higher temperature provided greater signals, especially for high viral concentrations, $\mathrm{A}(\mathrm{H} 1 \mathrm{~N} 1)$ virus could be also detected at room temperature. c) ELISA performed at $34{ }^{\circ} \mathrm{C}$ and with different incubation times with the virus. Results show that the whole concentration range tested could be detected after a 30-min incubation. However, the highest signals were registered after incubating for $1 \mathrm{~h} 30 \mathrm{~min}$ and extending the incubation further did not improve the result.

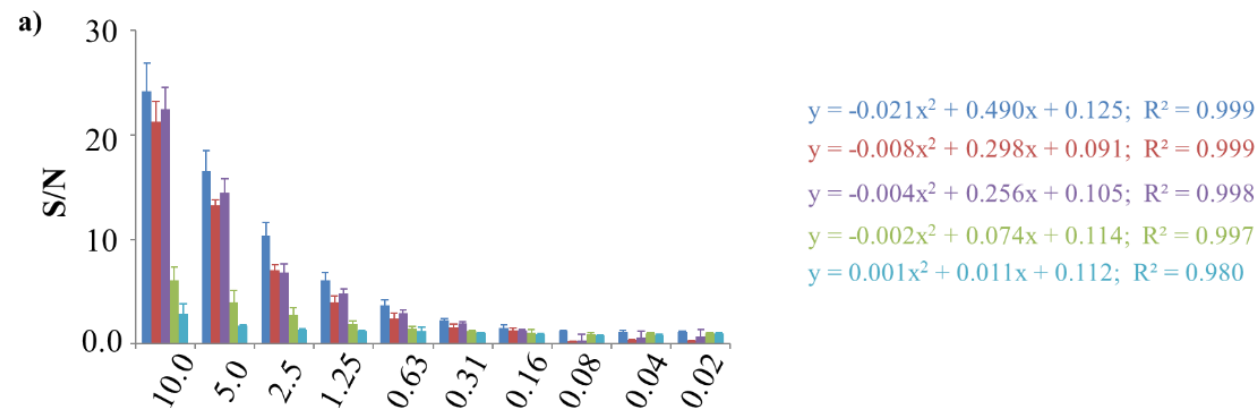

[Virus] $(\mu \mathrm{g} / \mathrm{mL})$
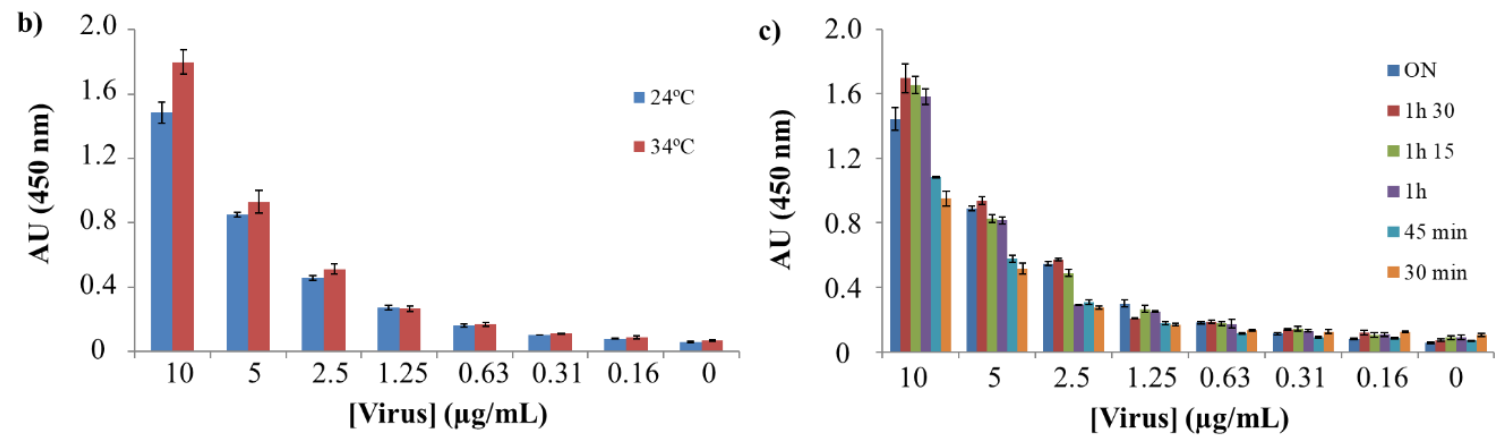


\section{Figure S6. Changes in sedimentation of sialylated beads in the presence of lectins.}

Sicastar-blue particles, $5 \mu \mathrm{m}$ (a) or $10 \mu \mathrm{m}$ (b) in diameter, were modified with the different sialylated proteins tested: GYPA and Av, two highly glycosylated proteins for which the specific sialic acid content could not be obtained; BM, which displayed a sialic acid content in a range of 9-24\%; and PM, which had a sialic acid content below $1.2 \%$.

The modified beads were then incubated for $15 \mathrm{~min}$ in U-shaped wells $\left(7.125 \times 10^{6}\right.$ and $8.25 \times 10^{5}$ beads/well for 5 and $10 \mu \mathrm{m}$ beads, respectively) with 10 -fold serial dilutions of 3 different lectins that, according to the provider's description, exhibited different carbohydrate-binding tropism:

1) Wheat germ agglutinin from Triticum vulgaris (WGA; ref L9640, Sigma) has affinity mainly for $\mathrm{N}$-acetyl- $\beta$-D-glucosamine oligomers, although it also recognizes Neu5Ac. WGA displays a hemagglutination activity $<20 \mu \mathrm{g} / \mathrm{mL}$, expressed as the lowest concentration needed to agglutinate a $2 \%$ suspension of human erythrocytes after 1 hour of incubation at $25^{\circ} \mathrm{C}$. This activity is not blood group specific.

2) Lectin from Sambuccus nigra (SNA; ref L6890, Sigma) interacts mostly with $\alpha$-NeuNAc[2 $\rightarrow 6]-G a 1, N e u 5 A c \alpha 2-6 \mathrm{Gal}(\mathrm{NAc})$, the same receptor as human influenza viruses, and, to a lesser extent, $\alpha$-NeuNAc-[2 $\rightarrow 3]$-Gal residues. It displays $\leq 4 \mu \mathrm{g} / \mathrm{mL}$ hemagglutination activity in the presence of human blood group A erythrocytes.

3) Lectin from Maackia amurensis (MAA; ref L8025, Sigma) interacts mostly with Neu5Aca2-3Gal(Nac), a similar receptor than avian influenza viruses. Displays $<10 \mu \mathrm{g} / \mathrm{mL}$ hemagglutination activity specific for blood group $\mathrm{O}$ erythrocytes.

As it can be observed in the images, 5 and $10 \mu$ m modified beads displayed similar trends, setting down when they were incubated alone, and changing the sedimentation in the presence of increasing concentrations of agglutinating lectins. GYPA-beads were better recognized by SNA, which displayed the highest affinity for Neu5Aca2-6Gal(NAc), the sialic acid characteristic of human erythrocytes, and the highest agglutination activity $(\leq 4 \mu \mathrm{g} / \mathrm{mL})$. It followed WGA, which could also bind Neu5Aca2-6Gal(NAc), although with lower agglutination activity ( $<20 \mu \mathrm{g} / \mathrm{mL})$. The worse recognition was provided by MAA, which binds preferentially avian-like Neu5Ac $\alpha 2-$ $3 \mathrm{Gal}(\mathrm{Nac})$ sialic acid receptors.

BM-beads seemed more sensitive to the presence of WGA, but responded to concentrations 10times higher of either SNA or MAA. In the case of PM-beads, they bound WGA and SNA, but did not respond to the presence of MAA, suggesting that this protein had little or no Neu5Aca2$3 \mathrm{Gal}(\mathrm{Nac})$ receptors.

Finally, Av-beads did not sediment, neither in the absence or in the presence of the 3 lectins tested. 
a)

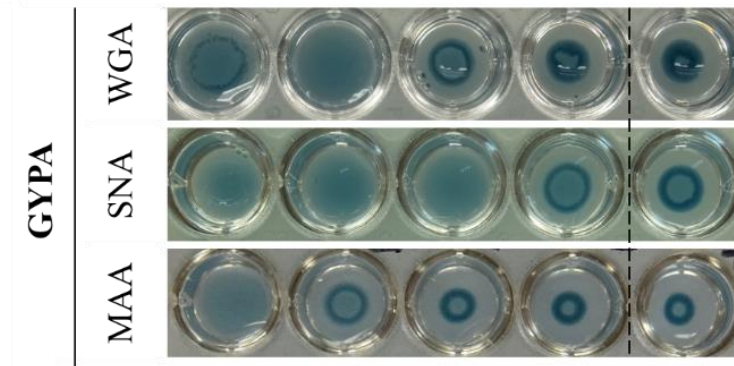

$3 \bigcirc(0) 0$

$\sum_{\infty}$
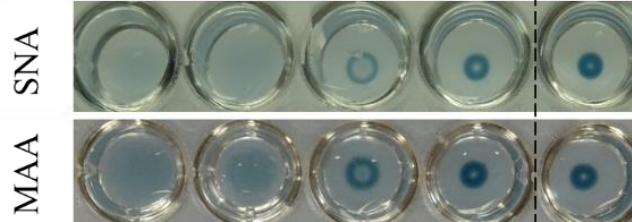

$\Rightarrow$ (a) $(5))^{\circ}$
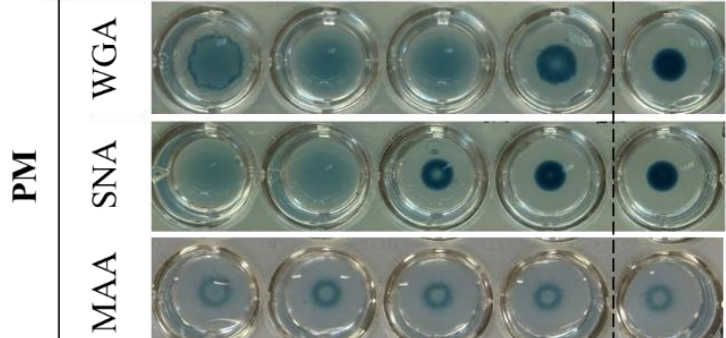

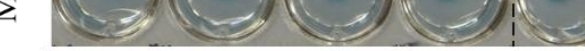

焉

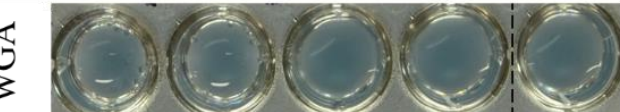

b) $\quad 10 \mu \mathrm{m}$ particles
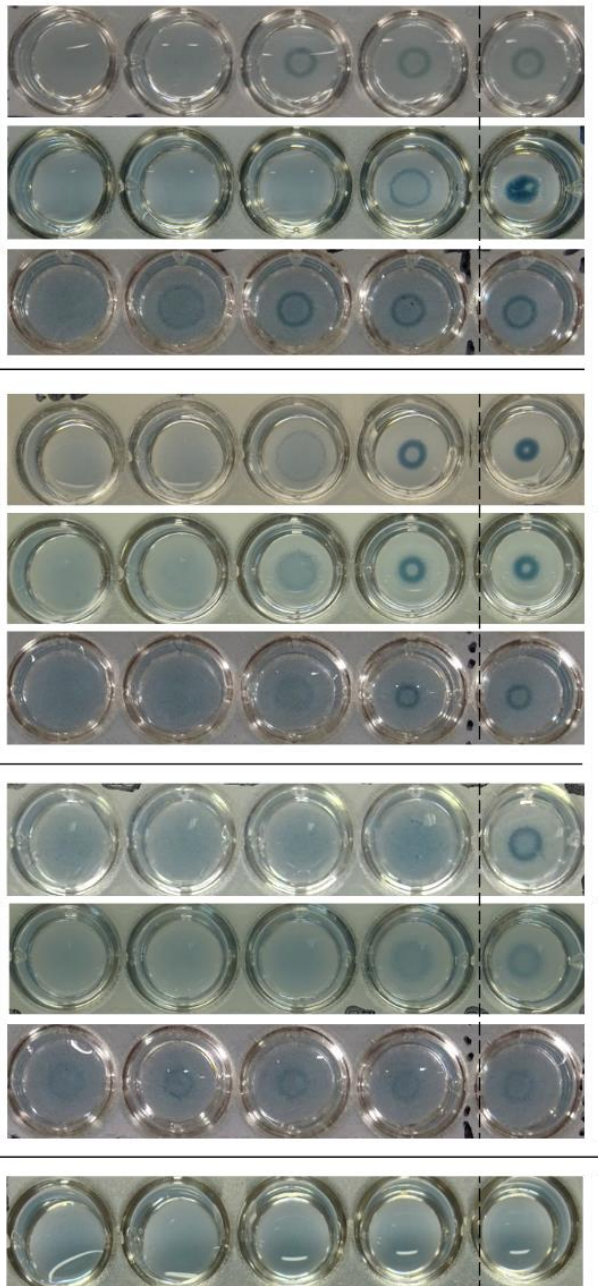

50

$0.05 \quad 0$

[Lectin] $(\mu \mathrm{g} / \mathrm{ml})$ 


\section{Figure S7. Impact of pH in the sedimentation of sialylated microparticles.}

Microparticles modified with the 4 sialylated proteins studied (GYPA, Av, BM and PM) were incubated for $10 \mathrm{~min}$ in $150 \mathrm{mM} \mathrm{NaCl}$ adjusted to different pHs. Red bars mark approximately the isoelectric point (Ip) for each sialylated protein. As it can be observed, the solution $\mathrm{pH}$ had a profound effect in microparticle sedimentation, which correlated with the Ip of the protein exhibited on surface. In general, the beads sedimented at $\mathrm{pH}$ above the Ip of the conjugated protein. Although below this Ip the beads did not form evident sediments, the microscopic observation revealed that the beads were not agglutinated. This suggested that the change in sedimentation was related to the negative charge displayed by proteins below their Ip, which impelled repulsion between individual beads, preventing the formation of tight sediments. This was consistent with the observation that avidin-coated particles ( $I p>10)$ only formed clear pellets in highly acidic buffers, when the protein presumably suffered $\mathrm{pH}$-induced denaturation. The fact that avidin-particles did not sediment clearly at neutral $\mathrm{pH}$ made them useless for virus detection, which is usually performed at $\mathrm{pH} 7$.

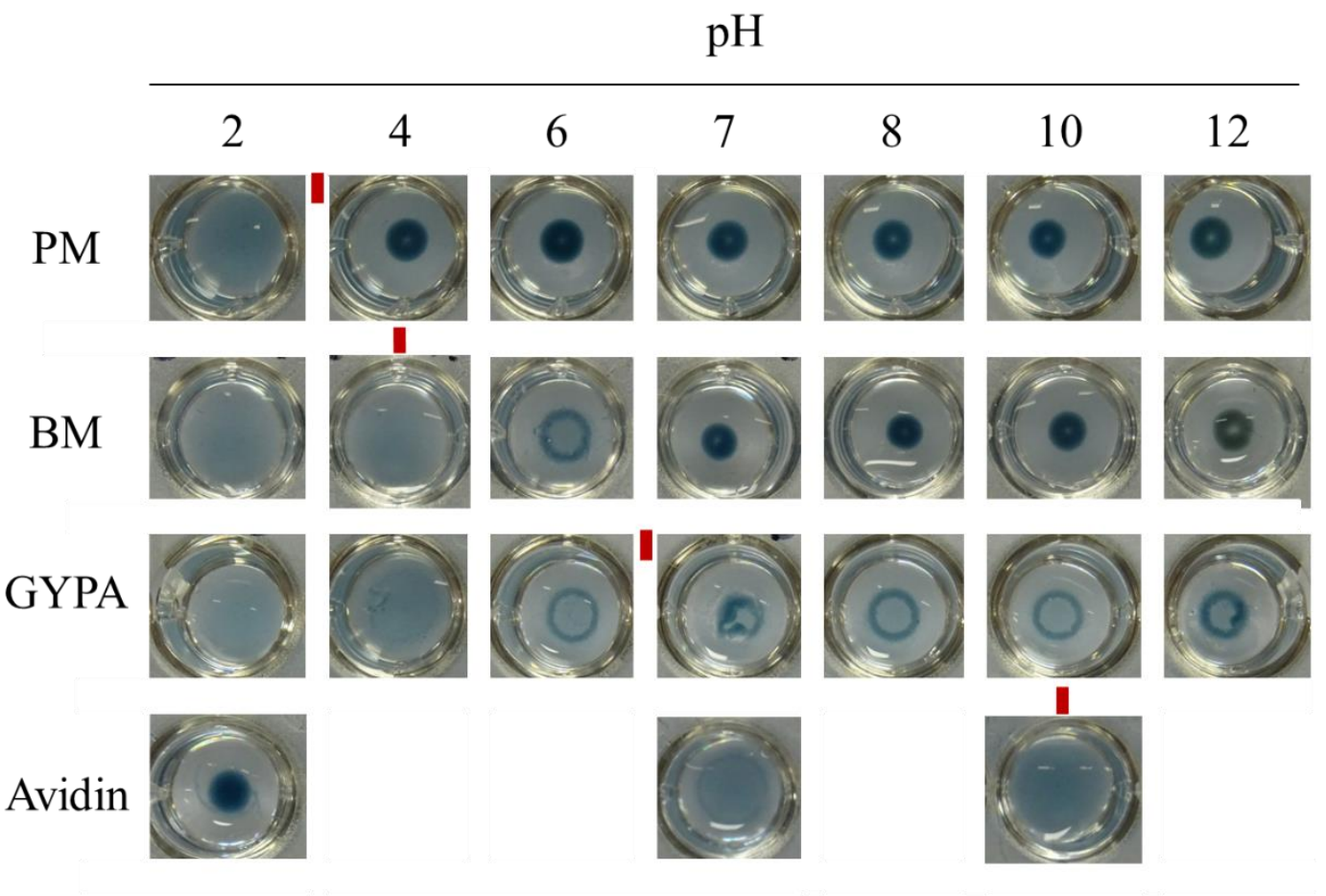


Figure S8. Effect of size of the sialylated beads in sedimentation capacity.

$250 \mu \mathrm{L}$ of sialylated silica beads of the same material and density but different size were allowed to sediment in a microtube with PBS for $1 \mathrm{~h}$. Pictures were took at different times to show the difference in sedimentation speed between them. As it can be observed, the higher the size (and weight) of the particle, the faster the sedimentation process. Particles above $10 \mu$ m sedimented too fast, which made their handling more complex.

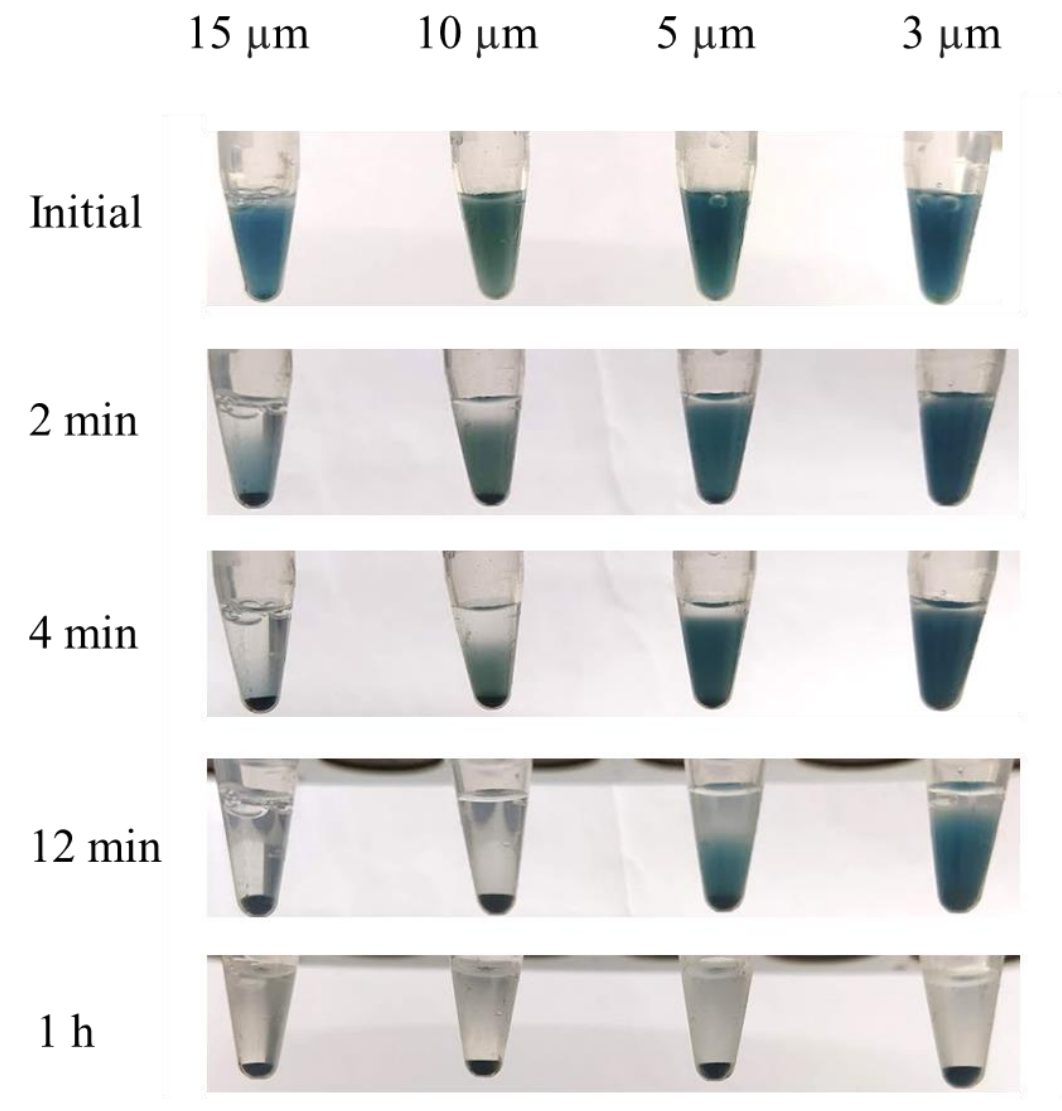




\section{Figure S9. Behavior of EDC- and glutaraldehyde-conjugated GYPA-particles in absence}

or presence of WGA lectin.

$5 \mu \mathrm{m}$ particles, displaying on surface either $\mathrm{COOH}$ or $\mathrm{NH}_{2}$ reactive groups, were conjugated with 3 different concentrations or $\mathrm{BM}(200 \mu \mathrm{g} / \mathrm{mL}, 100 \mu \mathrm{g} / \mathrm{mL}$ and $50 \mu \mathrm{g} / \mathrm{mL})$ using EDC or glutaraldehyde cross-linking, respectively. The modified beads were then incubated for $5 \mathrm{~min}$ in a U-bottomed plate with increasing concentrations of WGA (1.1 x1 $10^{6}$ particles/well). The results revealed that glutaraldehyde-conjugated particles sedimented forming darker and tighter pellets than the particles conjugated through EDC chemistry. This was attributed to the unreacted $\mathrm{COOH}$ groups present on the beads' surface which, consistently with the results summarized in Figure S5, could induce repulsion between individual particles and prevent tight sedimentation. In agreement with this observation, glutaraldehyde particles were selected for subsequent experiments.

Although in these experiments the best sensitivity was apparently displayed by particles modified with $50 \mu \mathrm{g}$ of $\mathrm{BM}$, later experiments showed that this was caused by non-specific binding.

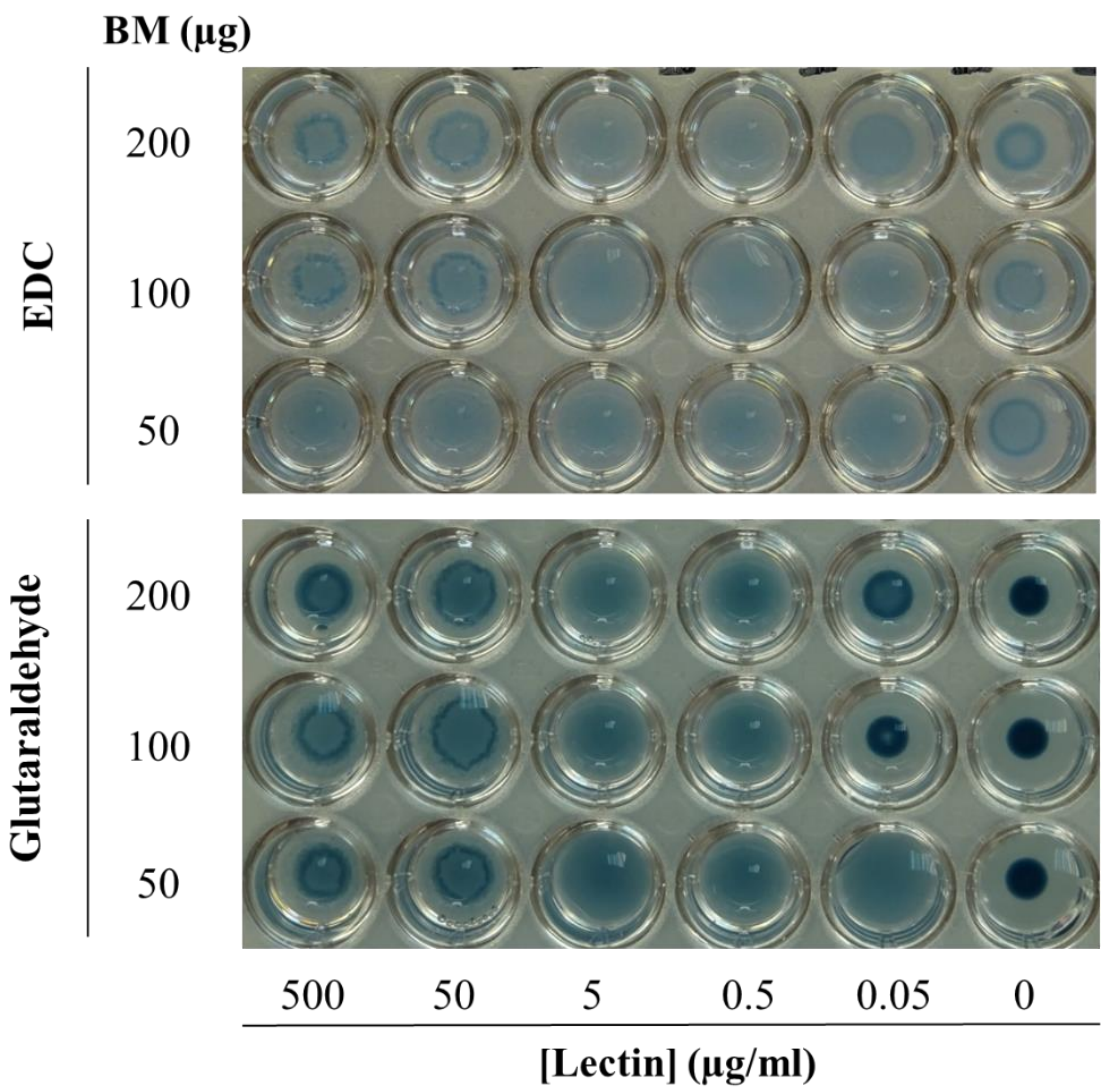




\section{Figure S10. Optimization of bead conjugation and assay.}

a) Comparative of two types of agitation, end-to-end mixing and vortex, imposed during bead conjugation. In both cases, $12.5 \mathrm{mg}$ of $5 \mu \mathrm{m}$ particles were incubated for $2 \mathrm{~h}$ in continuous agitation with $300 \mu \mathrm{g}$ of $\mathrm{BM}$ dissolved in $1 \mathrm{~mL}$ of PBS. Particles produced with vortex-mixing were two-fold more sensitive than those prepared by end-to-end mixing. b) Influence of the conjugation volume in the sensitivity of BM-coated particles. In these experiments, a fixed amount of particles was activated with glutaraldehyde $8 \%$ and then conjugated in reaction volumes ranging between $250 \mu \mathrm{L}$ and $1 \mathrm{~mL}$ at a fixed BM concentration $(300 \mu \mathrm{g} / \mathrm{mL})$. The best results were obtained for particles conjugated with $\mathrm{BM}$ in a final volume of $0.5 \mathrm{~mL}$, which allowed also reducing the amount of sialylated protein needed, decreasing the final cost of the synthetic reagent. c) Effect of the amount of conjugated bead used per well in the performance of the agglutination assays. Different amounts of $5 \mu \mathrm{m}$ BM-beads were incubated in the presence of increasing concentrations of WGA lectin. Higher particle loads produced darker and tighter sediments, which were easier to interpret visually, but were also less sensitive to the presence of the agglutinating lectin. For instance, while the use of 500-750 $\mu \mathrm{g}$ of beads/well allowed detecting WGA at concentrations above $5 \mu \mathrm{g} / \mathrm{mL}$, using 250-375 $\mu \mathrm{g}$ of beads/well permitted detecting WGA concentrations higher than $0.5 \mu \mathrm{g} / \mathrm{mL}$ However, the sediments produced by $375 \mu \mathrm{g}$ of beads/well were more consistent across experiments, which made us select these conditions for subsequent experiments.

a)

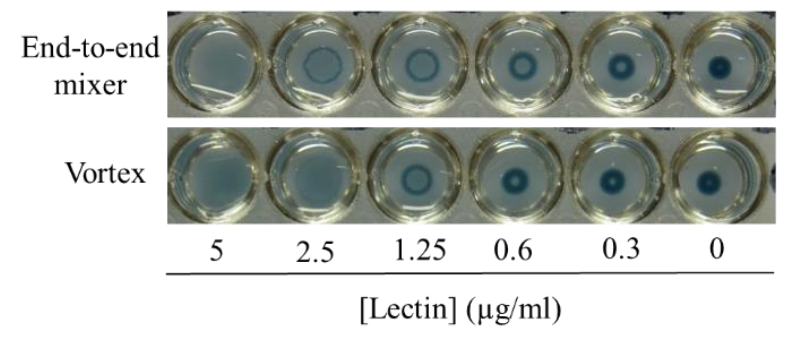

b)

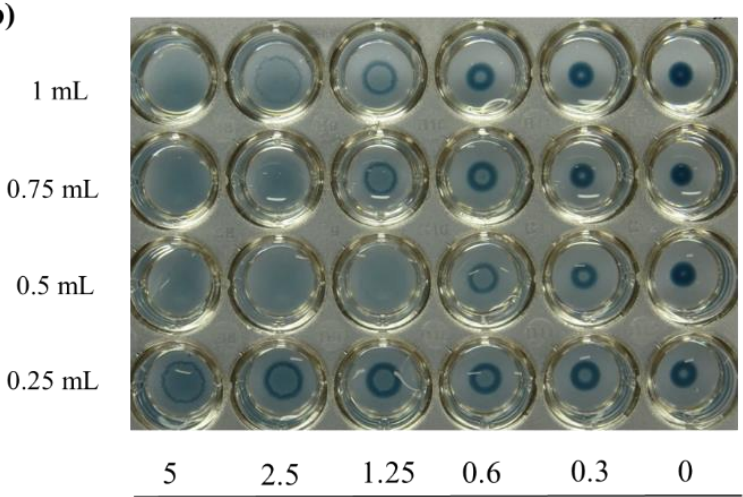

c)

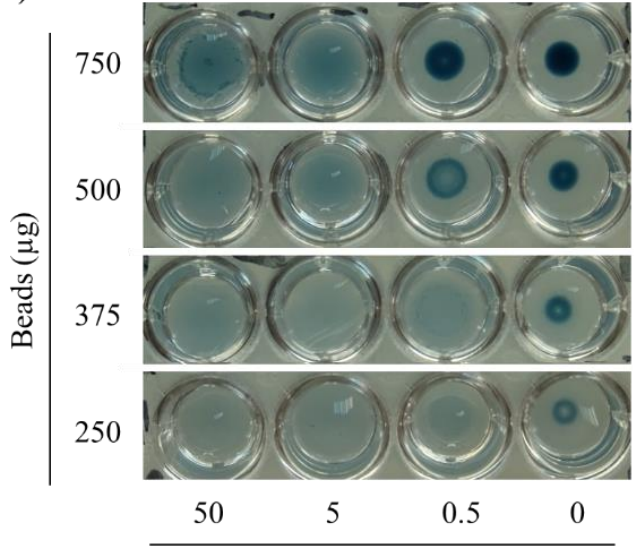

[Lectin] $(\mu \mathrm{g} / \mathrm{ml})$

[Lectin] $(\mu \mathrm{g} / \mathrm{ml})$ 


\section{Figure S11. Titration of the WHO reference antigens using alternatively synthrocytes or}

\section{human RBCs.}

These experiments were carried to determine, for each influenza strain, the virus dilution needed to perform agglutination inhibition assays. This was equivalent to 4 hemagglutination units for RBCs (the standard for HAI) and 8 agglutination units for synthrocytes (that provided the best results in the experiments).

RBCs were washed prior to use. Approximately $10 \mathrm{~mL}$ of RBCs were centrifuged for $5 \mathrm{~min}$ at 400 G. After discarding the supernatant, RBCs were washed with $50 \mathrm{~mL}$ of PBS followed by another 5 min centrifugation. This process was repeated 4 times. After the last centrifugation, the supernatant was totally removed. The pelleted RBCs (considered to be at a 100\% concentration) were then resuspended in PBS to a final concentration of $0.75 \%$.

Two-fold serial dilutions of the antigens ( $50 \mu \mathrm{L}$ per well) were mixed in the wells of a U-bottomed microtiter plate with $50 \mu \mathrm{L}$ of RBCs $(0.75 \%)$ or synthrocytes $\left(8.25 \times 10^{5}\right.$ beads in $50 \mu \mathrm{L}$ of PBS). These mixtures were then incubated for $1 \mathrm{~h}$ (human RBCs) or $10 \mathrm{~min}$ (synthrocytes). The highest dilution of virus that caused complete (hem)agglutination was considered 1 HA unit (HAU).

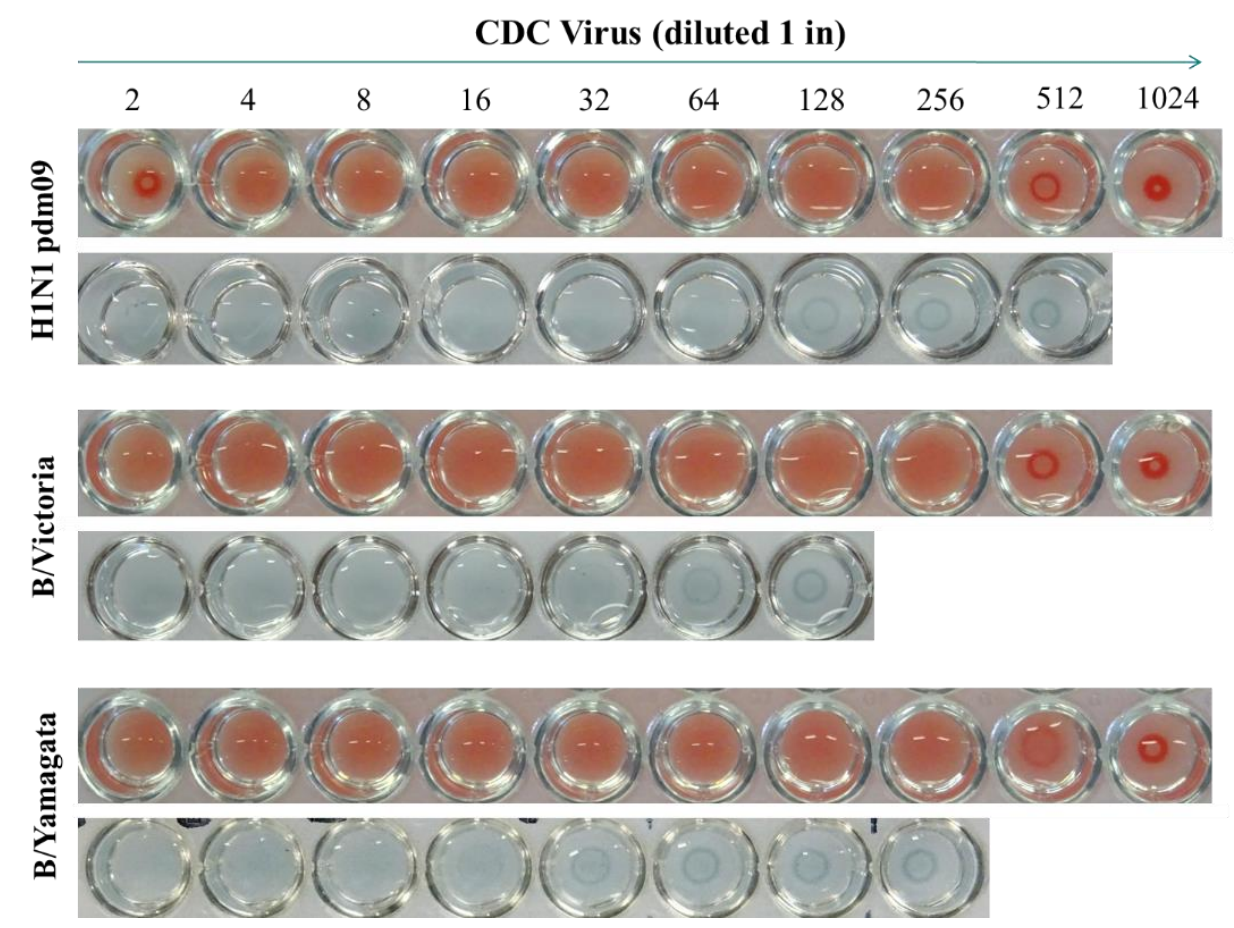


Video 1. Sedimentation of Sicastar blue particles in the presence of an agglutinating lectin.

Sicastar blue particles, $10 \mu \mathrm{m}$ in diameter, were modified with BM, were resuspended in PBS and were allowed to sediment in U-shaped wells in the absence and in the presence of an agglutinating agent (WGA lectin in this case).

Video 2. Sedimentation of synthrocytes in the presence of influenza virus.

Synthrocytes (Sicastar blue particles, $10 \mu \mathrm{m}$ in diameter, modified with GYPA) were allowed to sediment in U-shaped wells in the absence and in the presence of influenza virus (H1N1). As it can be observed, sedimentation occurs within $5 \mathrm{~min}$. While synthrocytes sediment over time, forming a ring pattern at the bottom of the well, in the presence of influenza virus the solution remains unsettled.

\section{References}

(1) Tayyab, S.; Qasim, M. A. Biochemistry and roles of glycophorin A Biochem. Educ. 1988, $16,63-66$.

(2) Marchesi, V. T.; Furthmayr, H.; Tomita, M. The red cell membrane. Annu. Rev. Biochem. 1976, 45, 667-698.

(3) Aoki, T. A Comprehensive Review of Our Current Understanding of Red Blood Cell (RBC) Glycoproteins. Membranes (Basel). 2017, 7, 56. 